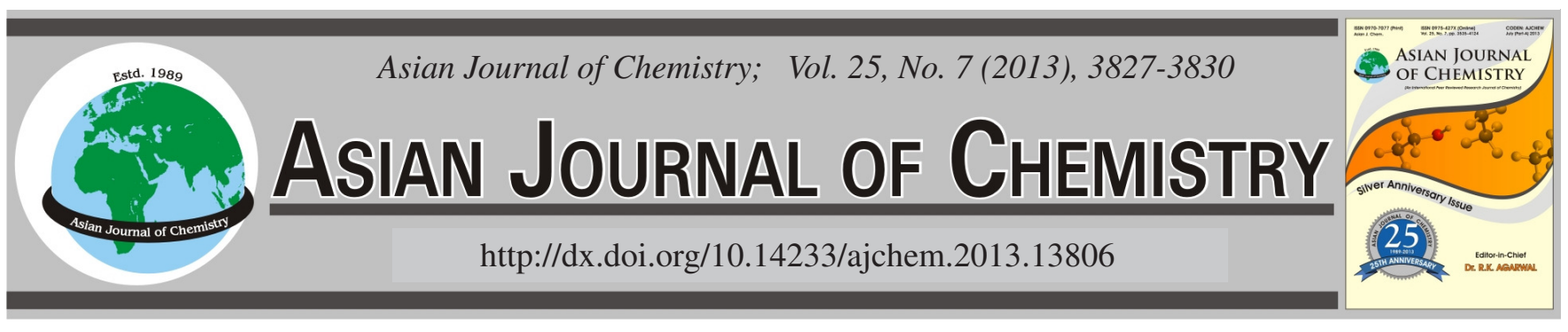

\title{
HPTLC Method Development and Validation of Secondary Metabolite-Thymol from Sufof-E-Mohazzil: A Unani Formulation
}

\author{
Avinash G. Patil ${ }^{1, *}$, Aqsa Y. Ansari ${ }^{1}$, Swapneel P. Koli ${ }^{1}$ and Darshana A. Patil ${ }^{2}$
}

${ }^{1}$ Department of Botany-Herbal Sciences, Birla College, Kalyan-421 304, India

${ }^{2}$ Department of Botany, Smt. Chandibai Himathmal Mansukhani College, Ulhasnagar-421 003, India

*Corresponding author: E-mail: dravinashpatil@ rediffmail.com

(Received: 28 March 2012;

Accepted: 14 January 2013)

AJC-12703

\begin{abstract}
Chromatographic techniques can be used to document phytochemical fingerprints and quantitate chemical markers in the herbal raw material. Sufoof-e-mohazzil (SM) is one of the most trusted and sold Unani formulation. Sufoof-e-mohazzil which has been used in Unani Pharmacy since antiquity is used as antiobesity agent, digestive and for controlling high cholesterol levels. Thymol as phytochemical marker was quantified using HPTLC from in-house and two marketed formulations (SM-1 and SM-2) of Sufoof-e-mohazzil. Quantification was carried out on silica gel $60 \mathrm{~F}_{254}$ pre-coated HPTLC plates using toluene: ethyl acetate: GAA [97:3:0.2, (v/v/v)] as mobile phase. The response was linear over the range of $1 \mu \mathrm{g} / \mathrm{mL}$ to $5 \mu \mathrm{g} / \mathrm{mL}$ with correlation coefficient of 0.986 . Accuracy of the method was checked by recovery studies at three different levels and the average percentage recoveries were found to be $97.94 \pm 0.5$. The concentration of the thymol was found to be $2.780 \mu \mathrm{g} / \mathrm{mL}$ for in-house formulation whereas 2.180 and $1.768 \mu \mathrm{g} / \mathrm{mL}$ for SM-1 and SM-2 respectively. The method was validated for linearity, precision, accuracy and ruggedness and can be used for routine quality control of Unani formulation Sufoof-e-mohazzil.
\end{abstract}

Key Words: Sufoof-e-mohazzil, HPTLC, Thymol, Method validation.

\section{INTRODUCTION}

The world health organization has recognized the Unani system of medicine as an alternative system to cater the health care needs of human population. Traditional systems of medicine is being practiced worldwide and Unani is one of the most well-known traditional medicine systems and draws on the ancient traditional systems of medicine of China, Egypt, India, Iraq, Persia and Syria. It is also called Arab medicine. Unani is still popular in many Arab and East Asian countries. In fact Unani medicine and herbal products are gradually more being used in many countries where modern medicine is easily available. India has accepted it as one of the alternative health care system and has given it official status ${ }^{1}$.

Sufoof-e-mohazzil (SM) is one of the most trusted and sold Unani formulation among the Unani medicines available in the market. Sufoof-e-mohazzil which has been used in Unani Pharmacy since antiquity as anti-obesity agent, digestive and for controlling high cholesterol levels ${ }^{2}$. Herbal formulations show the number of problems when quality aspect is considered, this is because of nature of the herbal ingredients and different secondary metabolites present therein. Mainly, variation in the chemical profile of the herbals due to intrinsic and extrinsic factors (growing, harvesting, storage and drying processes) ${ }^{3-5}$.
Chromatographic fingerprint have been suggested to check for authenticity or provide quality control of herbal medicine ${ }^{6}$. The world health organization accepts fingerprint chromatography as an identification and quality evaluation technique for medicinal herbs since $1991^{7}$. Fingerprints can be a unique identification utility for herbs and their different species $^{8,9}$ and can be used for modeling pharmaceutical activities ${ }^{10}$. Now days, chromatographic fingerprint technique plays an important role in controlling the quality of traditional Chinese medicines for the systemic characterization of compositions of samples and focusing on the identification and assessment of the stability of the components ${ }^{11}$. According to Shailajan and Sharma HPTLC study provides a chromatographic fingerprint of phytochemicals and is suitable for confirming the identity and purity of medicinal plants raw materials ${ }^{12}$. The British Herbal Pharmacopoeia has had an emphasis on using TLC profiles (fingerprint) to characterize herbal materials, relying on the use of different spray reagents and to identify and characterize active principles of herbal materials ${ }^{13}$. Chromatographic (HPTLC) fingerprinting of polyherbal formulations has also been reported by Chauhan et al.,$^{14}$.

Thin layer chromatography (TLC) and high performance thin layer chromatography (HPTLC) are commonly applied 
for the identification, to assay and for testing purity, stability, dissolution and content uniformity of raw materials (herbal and animal extracts, fermentation mixtures, drugs and excipients) and formulated products (pharmaceuticals, cosmetics, nutriments). These flexible and cost-effective techniques present the advantage of the simultaneous processing of standards and samples with versatile detection possibilities, including a great variety of post-chromatographic derivatization reagents ${ }^{15}$.

Thymol is one of the major constituent of three ingredients (Tranchyserimum ammi Linn. Fruit, Origanum vulgare Linn. Stem and Carum cavri Linn. fruit) used in the preparation of Sufoof-e-mohazzil ${ }^{16,17}$. Thymol shows 30 times higher antiseptic effect and four times lower toxicity than phenol ${ }^{18}$. Since this phenolic component of the above mentioned plants is considered as active constituents, most of the pharmaceutical dosage forms are standardized according to their thymol content $^{19}$. Therefore, thymol as phytochemical marker was quantified using HPTLC from in-house and two marketed formulations SM-1 and SM -2.

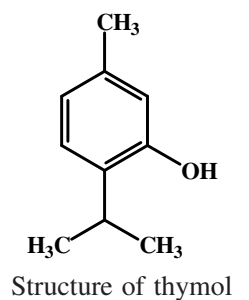

Thymol also known as 2-isopropyl-5-methylphenol (IPMP) is a natural monoterpene phenol derivative of cymene $\left(\mathrm{C}_{10} \mathrm{H}_{14} \mathrm{O}\right)$. The molecular weight of thymol is $149.66 \mathrm{Da}$, molecular mass of thymol is $150.22 \mathrm{~g} / \mathrm{mol}$ and density is 0.96 $\mathrm{g} / \mathrm{cm}^{3}$. Melting point of thymol is $49-51{ }^{\circ} \mathrm{C}$ and boiling point is $232{ }^{\circ} \mathrm{C}$. Thymol is very slightly soluble in water. It is used as a highly effective fungicide and insecticide ${ }^{20}$. Recent medical research on rats concludes that Thyme extract had relaxing effects on organs possessing $\beta_{2}$-receptors (uterus and trachea) $)^{21}$.

The advances in chromatographic techniques made it possible to quantify the chemical constituents in a mixture with comparatively little clean-up using HPTLC 22 . HPTLC method for identification of thymol from plants like Thymus vulgaris L. has been reported in literature ${ }^{23}$. However, HPTLC method for quantification of thymol from Sufoof-e-mohazzil has not been reported in literature. Therefore, present study deals with development and validation of a simple, specific, sensitive and accurate HPTLC method for quantification of one of the important marker compound thymol present in Sufoof-e-mohazzil, in-house and two marketed formulations (SM-1 and SM-2). The proposed method was validated in compliance with ICH (International conference on Harmonization) guidelines ${ }^{24}$.

\section{EXPERIMENTAL}

Procurement of raw material and marketed formulations: Ingredients for the preparation of in- house formulation and two marketed formulations (SM-1 and SM-2) were procured from the authorized retail shop, Bhiwandi, Thane, India.
Preparation of Sufoof-e-mohazzil: Sufoof-e-mohazzil contains four medicinal plants, one mineral and one resin viz. Tranchysperimum ammi Linn. Fruit (4 parts), Origanum vulgare Linn. Stem (1 part), Laccafer lacca (resin) 2 parts, Foeniculum vulgare Mill. Fruit (4 parts), Carum cavri Linn. Fruit (4 parts) and Bora-bora Armani mineral (1 part). Sufoofe-mohazzil, in-house formulation was prepared in laboratory according to the reported method in Unani Materia Medica ${ }^{2}$.

Reference standards and reagents: Reference standard thymol was purchased from Hi-media. All the solvents used were of analytical grade and was procured from Hi-media (Mumbai, India).

Preparation of standard thymol solution: The stock solution of thymol was prepared in $10 \mathrm{~mL}$ standard amber colour volumetric flask, by dissolving $50 \mu \mathrm{g}$ of accurately weighed thymol in about $5 \mathrm{~mL}$ of toluene, followed by vortex and making up the total volume of solution to $10 \mathrm{~mL}$ with toluene. The above stock solution was further diluted with toluene to give solutions of appropriate concentrations ranging from $1-5 \mu \mathrm{g} / \mathrm{mL}$.

Preparation of sample extracts: Accurately weighed, $500 \mathrm{mg}$ of Sufoof-e-mohazzil powder (in-house formulation, SM-1 and SM-2) was taken in a dry, clean amber colour stoppered test tube (capacity $20 \mathrm{~mL}$ ). To this stoppered test tube, 10 $\mathrm{mL}$ of dichloromethane was added and the content was vortex for $15 \mathrm{~min}$ at room temperature $\left(28 \pm 2{ }^{\circ} \mathrm{C}\right)$. The content of the tube was filtered through Whatman filter paper No. 41 and the filtrate obtained was evaporated to dryness. The residue is dissolved in $10 \mathrm{~mL}$ of toluene and was used as sample solution of respective formulation for carrying out the experiment.

Chromatographic conditions: The samples $(5 \mu \mathrm{L})$ were spotted in the form of bands of width $8 \mathrm{~mm}$ and $12 \mathrm{~mm}$ apart, starting at $15 \mathrm{~mm}$ from the edge with the help of Camag microlitre syringe on pre-coated silica gel aluminum plate 60 $\mathrm{F}_{254}$ using Camag Linomat V sample applicator. Before use, plates were prewashed with methanol and dried in an oven at $105^{\circ} \mathrm{C}$.

The plates were developed up to the distance of $80 \mathrm{~mm}$ in a Camag twin trough chamber previously saturated with mobile phase for $30 \mathrm{~min}$ at room temperature. The mobile phase consisted of toluene: ethyl acetate: glacial acetic acid, in the volume ratio of 9.7:0.3:0.2. The chromatographic conditions had previously been optimized to achieve the best resolution and peak shape. After development, plates were dried under air current at room temperature. The plate was further derivatized with freshly prepared $1 \%$ anisaldehyde reagent and dried at room temperature. After drying plates were kept in oven at $110^{\circ} \mathrm{C}$ for 10 min before densitometric scanning ${ }^{17,24}$.

Densitometric scanning was performed at $533 \mathrm{~nm}$ in reflectance-absorbance mode using tungsten lamp with a Camag TLC Scanner III in conjunction with Wincats 9 version software. The presences of thymol in the samples were confirmed by overlaying the densitogram of samples with that of the thymol and by comparing their retention factor $(\mathrm{R} f)(0.41)$. The chromatographic plate of standard thymol and in-house and marketed formulations were shown in plate No. 1.

Linearity: Linearity was evaluated in the range of $1 \mu \mathrm{g} / \mathrm{mL}$ to $5 \mu \mathrm{g} / \mathrm{mL}$ for thymol on silica gel alumina plates using above 
chromatographic conditions. Each of these concentrations was applied on plate, the plate was developed and the detector response for different concentrations was measured. A graph was plotted using the peak area against concentration of thymol. The experiment was performed three times and the mean was used for the calculation.

Limit of detection (LOD) and limit of quantification (LOQ): In order to determine LOD and LOQ, blank toluene was spotted to determine signal to noise ratio. LOD was considered as 3:1 and LOQ as 10:1.

Precision: The method was validated in terms of instrumental precision, intra assay precision and intermediate precision. The instrumental precision was studied by analyzing the standard solution of thymol of concentration of $3 \mu \mathrm{g} \mathrm{mL}^{-1}$, in 12 replicates, in the chromatographic system under the specified condition. The intra assay precision method was studied by analyzing $100 \%$ concentration. The intermediate precision was evaluated by analyzing the standard solution in triplicate on three different days, under specified chromatographic conditions.

Ruggedness: Ruggedness of the method was checked by introducing small changes in the chromatographic parameters, such as mobile phase composition, spotting volume and detection wavelength to determine their influence on the $\mathrm{R} f$ and quantitative analysis.

Application of validated method for the quantification of thymol from Sufoof-e-mohazzil: The quantification of thymol was done using above validated HPTLC method. $5 \mu \mathrm{L}$ of the sample solution was applied as bands in 3 replicates, on the HPTLC plate, using a Camag Linomat V sample applicator and analysed using the optimized chromatographic conditions.

Accuracy: The recovery was used to evaluate the accuracy of the method. Accuracy of the method was tested by performing recovery studies at three different levels $(80,100$ and $120 \%$ addition). All the samples of sufoof-e-mohazzil (in house and marketed formulations) were spiked with the known amount of standard and the percent ratios between the recovered and expected concentrations were calculated.

\section{RESULTS AND DISCUSSION}

In the present study, thymol has been quantified from a Unani polyherbal formulation Sufoof-e-mohazzil by HPTLC densitometric method using silica gel HPTLC plates. The developed method was validated as per the ICH guidelines (Tables 1-3). It was found that thymol resolved well at $\mathrm{R} f 0.41$ (plate No. 1 A) using the solvent system of toluene: ethyl acetate: GAA [9.7:0.3:0.2 (v/v/v)]. Specificity of method was carried out by overlaying spectra of thymol with Sufoof-e-mohazzil and it was found to be specific at $533 \mathrm{~nm}$ (plate no. $1 \mathrm{~B}$ ).

Linearity: Under the above described experimental conditions, linear correlation between the peak area and applied concentration was found to occur in the concentration range of $1-5 \mu \mathrm{g} \mathrm{mL} \mathrm{m}^{-1}$. The correlation coefficient was found to be 0.986. The peak area (y) is proportional to the concentration of thymol (x) following regression equation $\mathrm{y}=1264.7 \mathrm{x}+628.44$. The linearity data given indicated, there was a good correlation between mean peak area and concentration of thymol. The experimentally derived LOD and LOQ for thymol were found

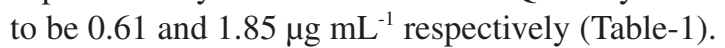

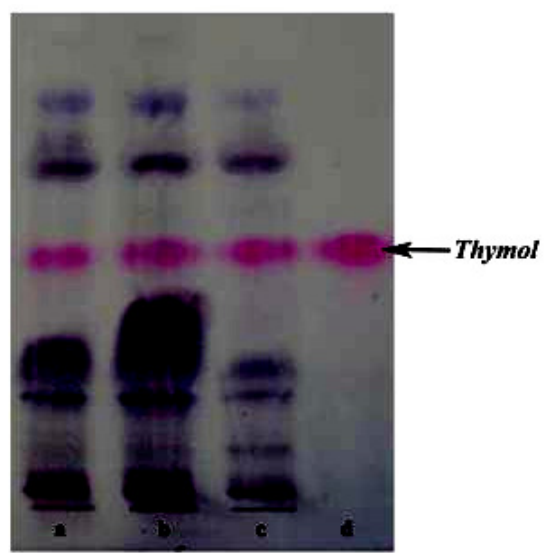

A

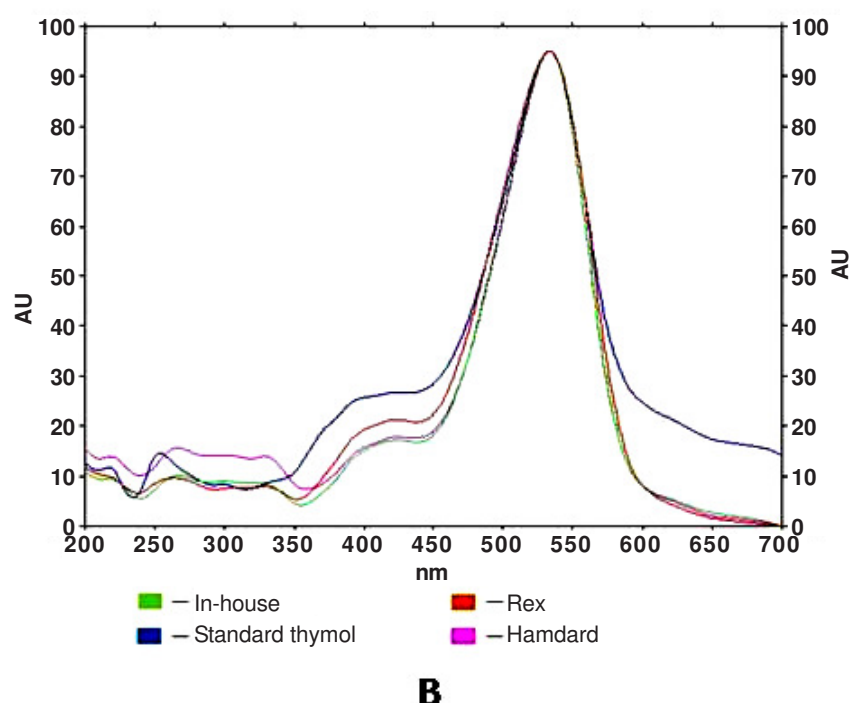

Plate no.1: A-HPTLC chromatogram of Sufoof-e-mohazzil with standard thymol; B-Spectra oveerlay of all formulations with standard thymol

\begin{tabular}{ll}
\multicolumn{2}{c}{ TABLE-1 } \\
\multicolumn{2}{c}{ LINEARITY DATA FOR THYMOL } \\
\hline Parameters & Thymol \\
\hline Linearity range & $1 \mu \mathrm{g} / \mathrm{mL}-5 \mu \mathrm{g} / \mathrm{mL}$ \\
Slope $(\mathrm{m})$ & 1264.7 \\
Intercept(c) & 628.44 \\
Correlation coefficient $(\mathrm{R})$ & 0.9864 \\
LOD & $0.61 \mu \mathrm{g} / \mathrm{mL}$ \\
LOQ & $1.85 \mu \mathrm{g} / \mathrm{mL}$ \\
Instrument precision $(\mathrm{n}=12, \% \mathrm{CV})$ & $0.46 \%$ \\
Intraday Precision $(\mathrm{n}=3, \% \mathrm{CV})$ & $2.03 \%$ \\
Interday Precision $(\mathrm{n}=3, \% \mathrm{CV})$ & $3.82 \%$ \\
\hline (Of the equation $\mathrm{y}=\mathrm{m} \mathrm{x}+\mathrm{c}$, where $\mathrm{y}=$ peak area, $\mathrm{m}=$ slope, $\mathrm{x}=$ \\
concentration, $\mathrm{c}=$ intercept)
\end{tabular}

Instrumental precision: Instrumental precision was checked by repeated scanning of the same band of thymol twelve times each. Standard thymol was spotted both at intraday (spotting three times within $24 \mathrm{~h}$ ) and inter-day (spotting three times within 3 days intervals) to check the precision. The results are expressed as \% CV (Table-1). The results 
expressed as \% RSD of peak area of thymol, are listed in Table-2. The results indicated that the method is precise and reproducible.

\begin{tabular}{lccc}
\multicolumn{4}{c}{ TABLE-2 } \\
\multicolumn{4}{c}{$\begin{array}{c}\text { RECOVERY STUDY OF THYMOL FROM } \\
\text { SUFOOF-E-MOHAZZIL }\end{array}$} \\
\hline Samples & $\begin{array}{c}\text { Amount } \\
\text { added }(\mu \mathrm{g})\end{array}$ & Recovery $(\%)$ & Mean recovery \pm SD \\
& \multicolumn{3}{c}{96.4} \\
SM -1 & 4.0 & 97.3015 & $96.60 \pm 0.63$ \\
& 4.8 & 96.12454 & \\
\hline \multirow{3}{*}{ SM-2 } & 3.2 & 97.3984 & $97.46 \pm 0.32$ \\
& 4.0 & 97.8054 & \\
& 4.8 & 97.18761 & $97.94 \pm 0.58$ \\
In-house & 4.0 & 98.362 & \\
& 4.8 & 97.28556 & \\
& 3.2 & 98.18761 & \\
\hline
\end{tabular}

Ruggedness: The method was found rugged for the parameters like change in mobile phase composition, change in spotting volume and detection wavelength. No significant change of $\mathrm{R} f$ or response to thymol was observed, indicating the ruggedness of the method.

Quantification of thymol in the formulations: The peak of thymol was confirmed by comparing the retention factor $(\mathrm{R} f$ ) of the sample with that of the standard solution of thymol having $\mathrm{R} f 0.41$ (plate no. $1 \mathrm{~A}$ ). An overlay of standard thymol with formulations used in the present study under above mentioned chromatographic condition is represented in plate no. $1 \mathrm{~B}$. The concentration of the thymol was found to be $2.780 \mu \mathrm{g} / \mathrm{mL}$ for in-house formulation whereas 2.180 and $1.768 \mu \mathrm{g} / \mathrm{mL}$ for SM -1 and SM -2 respectively (Table-3).

\begin{tabular}{lc} 
& TABLE-3 \\
& $\begin{array}{c}\text { THYMOL QUANTIFIED FROM DIFFERENT } \\
\text { SAMPLES OF SUFOOF-E-MOHAZZIL }\end{array}$ \\
\hline Sample & Content of thymol $(\mu \mathrm{g})$ \\
\hline SM-1 & $2.179 \pm 0.20$ \\
SM -2 & $1.685 \pm 0.04$ \\
In-house & $2.779 \pm 0.10$ \\
\hline
\end{tabular}

\section{Conclusion}

The HPTLC method developed for thymol is simple, rapid, selective, sensitive and economical and can be used for routine quality control analysis and quantification of thymol from various marketed formulations. Such reproducible modern techniques can make the traditional medicines more acceptable in the local and global market. Statistical analysis proved that the method is reproducible and selective for the analysis of thymol. Since the proposed mobile phase effectively resolves thymol, the method can be used for quality control analysis and quantitation of thymol. This strategy can be utilized for the estimation of thymol and chemical standardization of Sufoof-e-mozzahil and other herbal formulation containing thymol.

\section{REFERENCES}

1. A. Husain, G.D. Sofi, Tajuddin, R. Dang and N. Kumar, Med. J. Islamic World Acad. Sci., 18, 27 (2010).

2. K.H. Mohammad, Bayaz-e-Kabir. Hikmat Book Depot Hyderabad, edn. 15, vol. 2 (1977).

3. A.H. Gilani and A. Rahman, J. Ethanopharmacol., 100, 43 (2005).

4. WHO, Traditional Medicine Strategy 2002-2005 World Health Organization; Geneva (2002).

5. C. Zidorn, B. Schubert and H. Stuppner, Biochem. Syst. Eco., 33, 855 (2005).

6. T. Layloff, Pharm. Technol., 15, 146 (1991).

7. WHO, Guideline for the Assessment of Herbal Medicine, Munich, World Health Organization (1991).

8. Committee for Medicinal Product for Human Use (CHMP), Guidelines for the Quality of Herbal Medicinal Products/Traditional Herbal Medicinal Products. European Medicines Agency Inspections (2005). http:// www.emea.eu.int

9. W.J. Welsh, W.K. Lin, S.H. Tersigni, E. Collantes, R. Duta, M.S. Carey, W.L. Zielinski, J. Brower, J.A. Spencer and T.P. Layloff, Anal. Chem., 68, 3473 (1996).

10. Y.B. Ji, Q.S. Xu, Y.Z. Hu and Y.V. Heyden, J. Chromatogr. A., 1066, 97 (2005).

11. A.H. Liu, Y.H. Lin, M. Yang, H. Guo, S.H. Guan, J.H. Sun and D.A. Guo, J. Chromatogr. B, 846, 32 (2007).

12. S. Shailajan and A. Sharma, Asian J. Plant Sci., 7, 611 (2008).

13. British Herbal Pharmacopeia. British Herbal Medicine Association (1996).

14. B.L. Chauhan, S.K. Mitra, A.R. Mohan, S. Gopumadhavan and S.D. Anturlikar, Indian Drugs, 31, 333 (1994).

15. G. Szepesi, J. Planer Chromatogr. Mod. TLC, 6, 187 (1993).

16. M. Brigitte, The Desktop Guide to Herbal Medicine. Published by Elsevier, a division of Reed Elsevier (India) Private limited, New Delhi, edn. 1 (2007).

17. H. Wagner and S. Bladt, Plant Drug Analysis; A Thin Layer Chromatography Atlas. Berlin: Springer (1996).

18. Z. Zekovic, Z. Lepojevic and D.J. Vujic, Chromatographia, 51, 175 (2000).

19. H. Hajimehdipoor, M. Shekarchi, M. Khanavi, N. Adib and M. Amri, Pharmacog. Mag., 6, 154 (2010).

20. British Pharmacopeia, Published by British Government, edn. 5, vol. 2 (2005).

21. N. Wienkotter, F. Begrow, U. Kinzinger, D. Schierstedt and E.J. Verspohl, Planta Medica, 73, 629 (2007).

22. Quality Standards of Indian Medicinal Plants, Vol. I, Indian Council of Medical Research, New Delhi, vol. 1, pp.10-50 (2003).

23. A. Grigore, I.N.A. Paraschiv, S. Colceru-Mihul1, C. Bubueanu, E. Draghici and M. Ichim, Romanian Biotechnol. Lett., 15, 5436 (2010).

24. Q2A, ICH, Q2A (R1) Validation of Analytical Procedures: Text and Methodology, International Conference on Harmonization, Geneva (2005). 